\title{
The Domain Specificity of Academic Emotional Experiences
}

\author{
THOMAS GOETZ \\ ANNE C. FRENZEL \\ REINHARD PEKRUN \\ University of Munich \\ NATHAN C. HALL \\ University of California-Irvine
}

\begin{abstract}
The authors analyzed the domain specificity of emotions and focused on experiences of enjoyment, anxiety, and boredom in the domains of mathematics, Latin, German, and English. On the basis of assumptions in R. Pekrun's (2000; in press) control-value theory and findings of pilot studies, the authors hypothesized the existence of a largely domain-specific organization of emotional experiences. The sample consisted of 721 students from grades 7 to $\mathbf{1 0}$. Confirmatory multitrait-multimethod factor analysis of the 2-faceted dataset (emotions and domains) corroborated assumptions of domain specificity. Furthermore, using multilevel analysis, the authors found that emotions were significantly more domain-specific than students' grades, with enjoyment being the most domain-specific of the three emotions under investigation. The authors discuss implications for future research and practice.
\end{abstract}

Key words: achievement, anxiety, boredom, domain specificity, emotions, enjoyment

IS IT POSSIBLE TO INFER FROM STUDENTS' ENJOYMENT in mathematics classes that they will also enjoy other classes, such as science or English? The answer to this question is relevant from not only theoretical but also researchand practice-oriented perspectives, and not solely for enjoyment but for every emotional experience. For example, is representing the construct of test anxiety (Zeidner, 1998) as a highly generalized construct empirically justifiable? That is,

Address correspondence to: Thomas Goetz, Department of Psychology, University of Munich, Leopoldstr. 13, D-80802 Munich, Germany. E-mail: goetz@edupsy.unimuenchen.de 
does a student show a similar level of test anxiety across all academic domains, or does the intensity of the students' anxiety prove to be domain-specific, making it more appropriate to speak of domain-specific test anxieties such as mathematics test anxiety or English test anxiety? Does a single, domain-specific assessment of emotions suffice as a method of acquiring knowledge on emotional experiences across an entire array of domains? Can a mathematics teacher who notices that a student is often bored in math classes conclude that the student will also be bored in other domains?

These questions represent a critical area of investigation for theory and research on academic emotions. Although research examining emotional experiences related to learning and achievement is lacking, in recent years there has been a considerable increase in theoretical and empirical contributions to this field. This increased interest is reflected in two recent special issues on emotions and learning in the Educational Psychologist (Schutz \& Lanehart, 2002) and in Learning and Instruction (Efklides \& Volet, 2005). Despite this proliferation of research on academic emotions, few researchers have focused on the domain specificity of students' emotional experiences. Although this topic has already been investigated with respect to numerous constructs other than emotions (e.g., academic self-concept, achievement value; Bong, 2001), little empirical work exists on the domain specificity of academic emotions.

\section{Theoretical Assumptions}

One theoretical assumption consistently demonstrated by empirical research is that a number of psychosocial constructs other than emotions are organized in domain-specific ways. In particular, findings on the domain-specific organization of academic self-concepts are relatively clearcut (Marsh, 1993; Marsh \& Yeung, 1996). Many of those studies are based on Marsh's Internal/External Frame of Reference model ([I/E]; Marsh, 1986). In the I/E model, it is assumed that there are relatively strong relations between achievement scores in different domains (e.g., mathematics and languages), but that subjective beliefs and intraindividual comparison processes, regarding the domain-specific organization of individual abilities, lead to weak relations between self-concepts of abilities in these domains (e.g., "If I get a good grade in math, then I can't be especially good at German").

To test the assumptions of the I/E model, researchers investigate at least two different domains in a given study. More specifically, mathematics and languageoriented domains are the focus of most of these studies. Möller and Köller (2004) reported results from 34 studies on the I/E model and found a weak mean correlation ( $d=.10$, range $=-.13$ to .22 ) between mathematic and verbal academic selfconcepts. Besides academic self-concept, other variables have also been investigated with respect to their domain-specific organization, including self-efficacy, causal attributions, task values, and achievement goals (Abu-Hilal \& Bahri, 2000; 
Bong, 1998; Bong \& Skaalvik, 2003; Marsh, 1984, 1986; Möller \& Köller, 2001; Stevenson \& Newman, 1986).

It is reasonable to assume that the mechanisms underlying the domain specificity of such constructs as self-concepts, task values, and achievement goals are also at work for emotional experiences. Therefore, emotional experiences might be organized in a largely domain-specific manner. That is, the mechanisms addressed by Marsh's (1986) I/E model could operate for students' emotions as well. More specifically, Pekrun's (2000; in press) control-value theory of academic emotions represents a potentially valuable conceptual framework in which to examine the assumptions of the I/E model and apply available evidence on the domain specificity of motivational constructs to the field of emotions. Integrating assumptions from expectancy value (Pekrun, 1992; Turner \& Schallert, 2001) and attributional (Weiner, 1985) approaches to achievement-related emotions, Pekrun postulates that control and value appraisals relating to academic learning and achievement are of primary importance for students' emotions (Pekrun, 2000 in press; Pekrun, Goetz, Titz, \& Perry, 2002a). Control-related appraisals include self-directed beliefs underlying the subjective controllability of learning and its outcomes, with self-concepts of abilities being one type of relevant belief. Value appraisals include subjective task values and are closely related to students' achievement goals. Considering self-concepts, task values, and achievement goals are known to be organized in a largely domain-specific manner, Pekrun's control-value theory implies that resulting emotions should also be organized in domain-specific ways.

\section{Empirical Studies}

To date, empirical research on the domain specificity of students' emotional experiences is lacking. This lack is particularly true for the domain specificity of academic emotions other than anxiety. Within research on academic anxiety, two studies have explicitly addressed the domain specificity of this emotion (Marsh 1988a; Marsh \& Yeung, 1996). In addition, we found three studies that provide indirect evidence in support of the domain specificity of academic anxiety, although domain specificity was not explicitly stated as a primary research question (Everson, Tobias, Hartman, \& Gourgey, 1993; Gottfried, 1982; Hembree, 1990). With the exception of this research on academic anxiety, little empirical work on the domain-specific nature of academic emotions has been conducted. Thus, two preliminary investigations that more specifically addressed the domain specificity of other academic emotional experiences; these form the empirical framework on which the present study is based (Goetz, 2004; Pekrun, Goetz, Titz, \& Perry, 2002b).

Concerning studies on the domain specificity of anxiety, Marsh (1988a) concentrated his investigation on experiences of anxiety during instruction and 
found a disattenuated correlation of $r_{\mathrm{d}}=.04$ between anxiety in mathematics and English lessons (four items each, parallelized scales; $N=14,825$, grade 10; analysis of data from the High School and Beyond [HSB] Study; National Center for Educational Statistics [NCES], 1986). Marsh and Yeung (1996) examined anxiety in four academic domains (mathematics, sciences, social studies, and English) by analyzing data from the National Educational Longitudinal Survey of 1988 (NELS88 database, Ingles et al., 1992; $N=24,599$ eighth graders). Using confirmatory factor analyses, the authors demonstrated that academic anxiety in school-aged children is organized in a domain-specific way. They found very weak intercorrelations between domain-specific anxiety ratings, with the strongest relationships found between anxiety in conceptually similar academic domains (e.g., mathematics and science). Moreover, anxiety showed a greater degree of domain specificity than academic achievement in these domains (with grades as well as standardized test scores).

Everson et al. (1993) investigated the relations between subjective difficulty of a particular subject and test anxiety in that domain among first-year college students (average age $=21$ years). They found highly distinctive individual levels of test anxiety in English, mathematics, physics, and social studies. Analyzing the relationship between intrinsic motivation and anxiety, Gottfried (1982) investigated similar variables among 141 fourth and seventh graders in four academic domains (reading, mathematics, social studies, and sciences). Significant negative correlations were found between anxiety and intrinsic motivation within domains (e.g., intrinsic motivation and anxiety involving mathematics) but not between domains (e.g., intrinsic motivation in mathematics and anxiety related to reading). In a meta-analysis of 51 studies using the Mathematics Anxiety Rating Scale ([MARS]; Richardson \& Suinn, 1972), Hembree (1990) reported a mean correlation of $r=-.06$ between mathematics anxiety and verbal performance, as well as a correlation coefficient of $r=-.34$ between the MARS scores and mathematical performance. This finding points to the domain specificity of anxiety based on the premise that, if anxiety were organized in a domain-transcending manner, then higher MARS scores would predict more anxiety in verbal domains, which would translate into significantly poorer verbal performance than evidenced by Hembree's nonsignificant correlation.

Nevertheless, all of these studies pertained to anxiety. We conducted two pilot investigations to also obtain preliminary evidence concerning the domain specificity of academic emotions other than anxiety. Pekrun and colleagues (2002b) used Pekrun's (2000; in press) control-value theory of emotions to derive assumptions involving the relative domain specificity of students' academic emotions. Between-domain correlations in a sample of 697 middle school students were nonsignificant and near zero for academic enjoyment in mathematics, languages (German and English), music, and sports, and low for anxiety $(.13<r<$ .26). Goetz (2004; $N=699$, Grades 7 and 9 ) also found very weak correlations be- 
tween enjoyment in the domains of mathematics, German, English, music, and physical education. The corresponding correlations for anxiety were somewhat stronger. Taken together, the results of these two studies indicate that academic enjoyment and anxiety may be conceptually organized in a largely domain-specific manner, yet they may vary in their degree of domain specificity.

In sum, the available evidence suggests a domain-specific organization of students' anxiety. Empirical evidence on the domain-specific organization of emotions other than anxiety, however, is still largely lacking. Therefore, in the present study, we further explored the domain-specific nature of students' academic emotional experiences and more specifically, examined the relative degree of domain specificity in different academic emotions.

\section{Research Questions and Hypotheses}

We aimed to examine whether students' emotional experiences-namely experiences of academic enjoyment, anxiety, and boredom - are organized in a domain-specific manner. Because theoretical assumptions and the findings of our pilot studies suggest a domain-specific structure of academic emotions, we also anticipated a domain-specific organization of emotional experiences in the present study.

In addition to the analysis of the internal structures of emotional experiences (within-network), we wanted to investigate the external relations (betweennetwork) of academic enjoyment, anxiety, and boredom. We hypothesized substantial relations between emotional experiences and achievement in similar school subjects (e.g., English and German; convergent validity of emotion measures) and a relative lack of correlations between scores in dissimilar school subjects (e.g., mathematics and English) supporting the divergent validity of the emotions measures.

Furthermore, we also examined the extent to which enjoyment, anxiety, and boredom differ in their respective degrees of domain specificity. Based on the findings of the pilot research (Goetz, 2004; Pekrun et al., 2002b), we hypothesized that enjoyment would show a greater degree of domain specificity than with anxiety. Because there is a lack of research findings on the extent to which boredom is experienced as domain specific, the current study was exploratory in nature with respect to this specific academic emotion.

\section{Method}

\section{Sample and Data Collection}

Our sample consisted of 721 students (54\% female) from 32 classes within five schools (7th grade: $n=224$; 8 th grade: $n=154$; 9 th grade: $n=187$; 10 th 
grade: $n=156$; schools 1-5: $n=189,217,92,138$, and 85 , respectively). Data collection lasted $45 \mathrm{~min}$ per class and was conducted by trained testing personnel using fully standardized student questionnaires. The average age of the participants was 14.42 years $(S D=1.29)$; no significant gender difference existed, $t(719)=.99, p=.32$. Participation in the study was voluntary and required parental consent.

\section{Selection of Emotions and Academic Domains}

We used two selection criteria in choosing which emotions to assess. First, we wanted to assess emotions that were conceptually distinct. Numerous models for categorizing emotions based on underlying dimensions, such as activation, valence, intensity, and duration are available. We based our selection of emotions on Watson and Tellegen's (1985) circumplex model, which categorizes emotions according to aspects relevant in the context of learning and achievement, namely activation and valence. Second, we searched in the research literature for emotions that are particularly important in academic settings (see Goetz, 2004; Pekrun et al., 2002a). As a result of these two selection strategies, we chose to assess the following three emotions that have been found to be salient in an academic environment and could be distinguished based on activation and valence: enjoyment (positive and activating), anxiety (negative and activating), and boredom (negative and deactivating). With respect to the academic domains in which each of the three emotions were assessed, we selected major school subjects taught in all five of the schools and in each grade level: mathematics, Latin, German, and English.

\section{Measurement of Discrete Emotions in Various Academic Domains}

Single items developed within the Project for the Analysis of Learning and Achievement in Mathematics study (PALMA; Goetz, 2004; Pekrun, Goetz, \& Frenzel, 2006) were used to measure enjoyment, anxiety, and boredom in the domains of mathematics, Latin, German, and English (12 items in total). The four enjoyment items were "How much do you enjoy [domain]?" The four anxiety items were "How much anxiety do you experience in [domain]?" The four boredom items were "How much do you feel bored in [domain]?" Response format consisted of a 5-point Likert scale ranging from 1 (not at all) to 5 (very much). The Appendix shows the means and standard deviations as well as intercorrelations of all single emotion items.

We also administered three Latin-related multi-item emotion scales assessing enjoyment, anxiety, and boredom in this study to test the validity of the singleitem measures. The three multi-item scales were based on the PALMA scales and modified to pertain to the Latin domain. Response format for these three scales 
consisted of a 5-point Likert scale ranging from 1 (strongly disagree) to 5 (strongly agree). The scales showed the following statistical characteristics: $\alpha=$ $.88, M=24.97, S D=7.23$ for enjoyment (nine items); $\alpha=.91, M=35.40, S D=$ 11.95 for anxiety ( 15 items); and $\alpha=.91, M=15.15, S D=6.42$ for boredom (six items). Using linear structural equation modeling (LISREL 8.53; Jöreskog \& Sörbom, 2002), we calculated the sizes of effects from the three Latin-related single-item scales (enjoyment, anxiety, and boredom in Latin) to the corresponding Latin-specific latent variables (also enjoyment, anxiety, and boredom in Latin). All three path coefficients from the Latin-related single-item scales (manifest variables) to the corresponding multi-item scales (latent variables) were relatively high (.86 for enjoyment, .66 for anxiety, and .80 for boredom). Overall, these high path coefficients indicate that the measurement of emotions using single-item measures in the current study was sufficiently valid.

\section{Achievement}

We obtained achievement data for mathematics, Latin, German, and English from students' self-reported final grades for the preceding school year. In the German school system, grades vary between 1 (very good) and 6 (insufficient). Given that high values represent poor achievement outcomes is counterintuitive, we inverted the grades measure in subsequent analyses. Thus, high values on the inverted grades variable represent good achievement outcomes. Concerning the validity of students' self-reported final grades, a recent study by Dickhaeuser and Plenter (2005) showed very strong correlations $(r=.90)$ between self-reported and actual academic performance using a German sample of 866 students in grades 7 and 8. Furthermore, Dickhaeuser and Plenter also showed that the accuracy of the self-reported performance did not depend on students' gender or achievement level. Thus, one can assume that self-reported final grades assessed in the present study were sufficiently accurate indicators of students' actual grades. Means, standard deviations, and intercorrelations of the achievement scores (inverted grades) are presented in the Appendix.

\section{Data Analyses-Domain Specificity of Emotional Experiences}

The set of 12 items reflects an underlying two-facet design in which the emotion facet has three levels (enjoyment, anxiety, boredom) and the school subject facet has four levels (mathematics, Latin, German, English). As such, the dualfaceted emotion data collected in the present study can be viewed as multitrait-multimethod (MTMM) data, and confirmatory factor analysis (CFA) can be used to address our research question (Byrne, 1998; Marsh, 1988b; Widaman, 1985). A central advantage of analyzing MTMM data with CFA is that method effects can be taken into account when analyzing the traits. Method effects are 
often regarded as unwanted disruptive factors to be controlled for (Marsh \& Yeung, 1996); however, they can in fact reveal important information concerning the structure of the data (Marsh, Byrne, \& Craven, 1993). Because structural aspects played a pivotal role in the emotion measures employed in the current study, we analyzed our data in line with the analysis of the MTMM data.

To this end, we adapted an approach suggested by Marsh and Yeung (1996), in which linear structural equation modeling (LISREL 8.53; Jöreskog \& Sörbom, 2002) is used for testing a set of CFA-MTMM models competitively (see also Marsh, 1989). We tested a total of five models (A to E) depicted in Figure 1. In Model A, one latent general factor is defined. Because all 12 items of the twofacet design ( 3 emotion $\times 4$ domains) refer to one single factor, we termed this general factor Domain-Transcending Emotionality. In Model B, we defined three emotion-specific latent factors (experiences of enjoyment, anxiety, and boredom) with each domain-specific item for each emotion predicted by the latent factor for that emotion (e.g., all four enjoyment items were predicted by the latent enjoyment factor). We labeled each of the three factors of Model B a Domain-General Discrete Emotion representing the total of experiences of each of the three emotions across mathematics, Latin, German, and English. Finally, Model C included four domain-specific latent emotion factors (emotional experiences in mathematics, Latin, German, and English). That is, each of the three domain-specific items (e.g., enjoyment in mathematics, anxiety in mathematics, boredom in mathematics) was predicted by the latent factor representing the given domain, (e.g., mathematics). We labeled the four factors of Model C Domain-Specific Emotionality that is, the total of students' experiences of enjoyment, anxiety, and boredom in each of the four domains.

We did not assess a model in which emotions and domains were defined as traits simultaneously because previous researchers have indicated that such models typically result in unstable solutions (Marsh, Byrne, \& Craven, 1993). However, several researchers have shown that correlated uniqueness (CU, a combination of specific and error variance) models are suitable for this kind of analysis (Byrne, 1998; Marsh \& Grayson, 1995).One can assume that CU-MTMM models better fit the data than do models where method effects are not considered (Byrne; Marsh, Byrne, \& Craven). In both Models B and C, only one facet of the two-faceted data structure was taken into account in assessing the corresponding latent factors (Model B: Discrete Emotion factor; Model C: Domain factor). Consequently, both models could be modeled as CU-MTMM models, in which the other complementary factor would be accounted for as a method effect. However, both CU Models (CU-B, CU-C) had a similar structure that is, the effects of the emotion and domain factors were considered simultaneously in each model.

Because Model C was most applicable to our present research question concerning the strength of relationships between the emotional experiences in the different subject areas (i.e., the degree of domain specificity), we revised this 
model to include correlations between the discrete emotions in the different subject areas to control for correlated uniqueness among the similar emotion measures. Once again, we were more interested in the strength of relations involving the domain specificity of academic emotions (Model C) than the domain-general nature of discrete emotional experiences (Model B).

For building the CU-MTMM Model D, we defined the four domain-specific factors of Model C as Traits (domains = traits) and considered the emotion-specific item components method effects. Thus, Model D is a modified version of Model C and represents a CU-MTMM model with CU between items referring to the same emotional experience ( $18 \mathrm{CUs}$ in total: 4 items per emotion and, consequently, 6 CUs per emotion). That is, CUs between items with identical emotion-related item components were permitted in Model D $(4 \times$ "How much do you enjoy [domain]?;" $4 \times$ "How much anxiety do you experience in [domain]?;" $4 \times$ "How much are you bored in [domain]?"). In terms of the MTMM approach, no method factors were specified per se, but we considered their potential.

We integrated achievement outcomes in the four subject areas into the analysis as external criteria because, in addition to the internal structure (within-network) of Model D, the external validity (between-network) of the latent factors of this Model was to be tested. We generated Model E for that purpose and it represented an extension of Model D (see Figure 1). In this model, we integrated an achievement indicator (i.e., grades) for each of the four domains as a manifest variable in addition to the four domain-specific factors of Model D, with the error variance of each achievement score fixed to zero.

Testing was based on a comparison of the chi-square statistics and selected fit indices (Nonnormed Fit Index-NNFI, Tucker-Lewis Index-TLI; Tucker \& Lewis, 1973; Comparative Fit Index-CFI, Bentler, 1990; root mean square error of approximation [RMSEA] Steiger \& Lind, 1980). In line with Marsh and Yeung's (1996) methodological approach and in view of our large sample, the chi-square test was not integrated in our analysis as this test has been shown to be overly sensitive to sample size (e.g., Marsh, Balla, \& McDonald, 1988).

Both the NNFI and the CFI are incremental indices with goodness of fit scaled from 0 to 1 . The zero point represents a null model in which all the measured variables are assumed to be uncorrelated and the 1.0 point reflects a perfect fit. NNFIs and CFIs greater than .90 indicate an acceptable model fit, but for our purposes, a comparison of the fit indices for competing models was also important. CFI and NNFI differ from each other in that the CFI is insensitive to model complexity, whereas the NNFI corrects the fit according to the model complexity with more complex models typically resulting in poorer fit levels (for a more exact description of NNFI and CFI see Byrne, 1998). The RMSEA takes the error of approximation in the population into account and is also sensitive to model complexity. RMSEAs less than .06 indicate good fit, and values as high as .08 represent reasonable error of approximation in the population. 


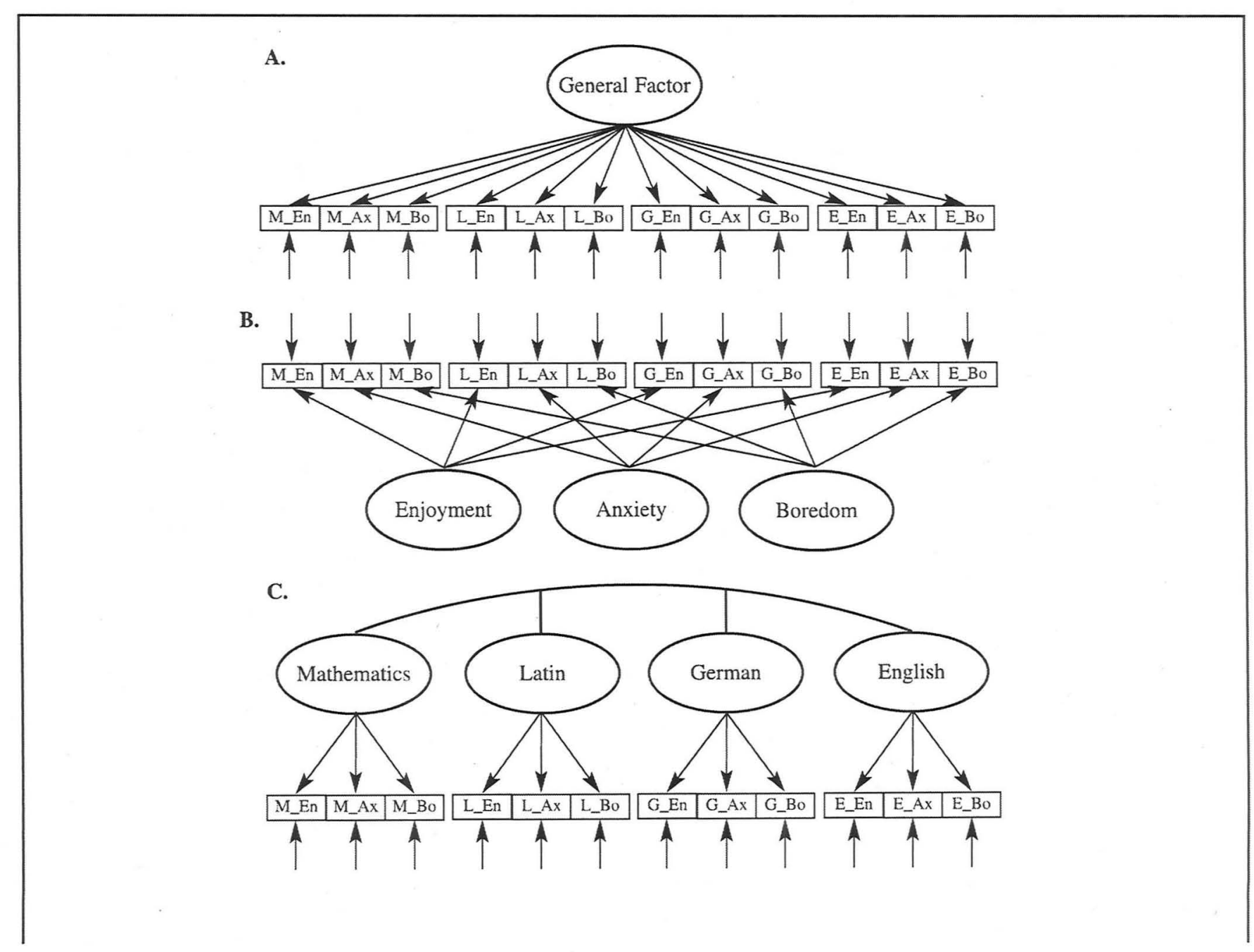


D.

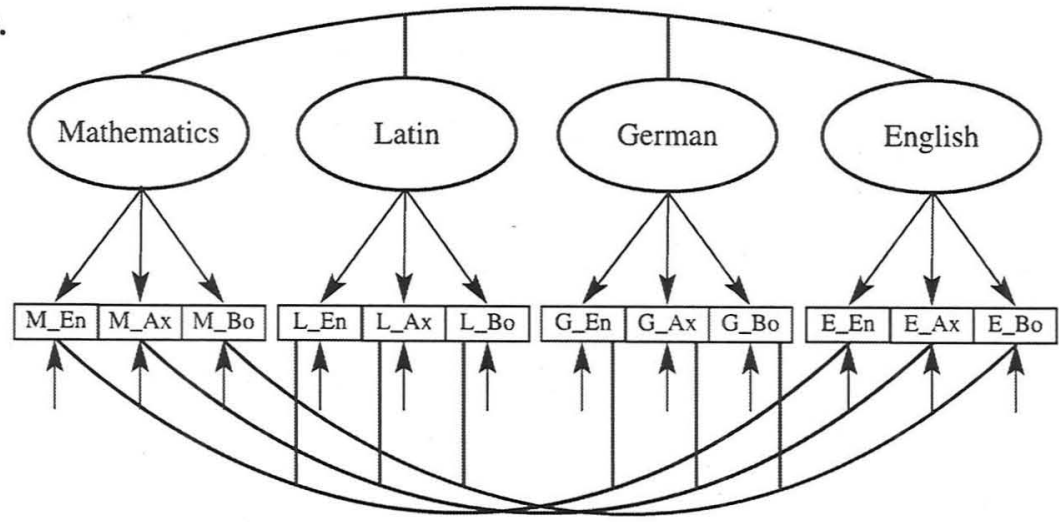

E.
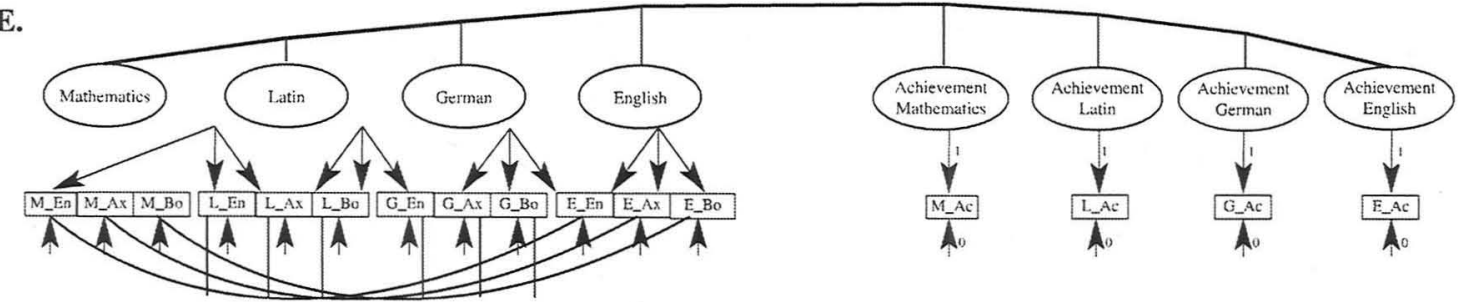

FIGURE 1. Structural model for the testing of domain specificity of emotional experiences. The 12 items measure the experience of En: enjoyment, An: anxiety, Bo: boredom in the domains of M: mathematics, L: Latin, G: German, E: English. Model A: General factor model (Domain-Transcending Emotionality). Model B: three emotion-specific factors (Domain-General Discrete Emotions). Model C: four domain-specific factors (Domain-Specific Emotionality). Model D: four domain-specific factors with correlated uniquenesses of emotion ratings (Correlated Uniqueness Model [CU-Model]; that is, assumption of domain-specific emotionality with consideration of the effects of the emotion-specific factors). Model E: identically equal to Model D (CU-Model), but achievement scores were integrated additionally as manifest variables. 


\section{Data Analyses-Domain Specificity of Discrete Emotions}

Because the confirmatory factor analyses provided no information concerning the extent to which enjoyment, anxiety, and boredom may vary in their domainspecific organization, we conducted a multilevel analysis procedure to answer that question (hierarchical linear modeling [HLM 6.01]; Raudenbush, Bryk, Cheong, \& Congdon, 2001). To examine the extent of domain specificity in the three emotions under investigation in relation to the external criterion we included achievement outcomes in each of the four domains in our analyses. First, a Level 1 dataset was created with four variables, namely enjoyment, anxiety, boredom, and performance. One row in this dataset represented the scores for these four variables for 1 participant in one domain. Thus, every participant had four rows of data with each row corresponding to one of the four domains assessed (mathematics, Latin, German, and English). The level 1 file thus included a total of 2,884 level 1 rows (721 [sample size] $\times 4$ [domains]).

To generate the level 2 dataset, we aggregated the data for each participant across the four domains for each of the four variables. For example, for enjoyment, we calculated the mean value of enjoyment in mathematics, Latin, German, and English for each participant. We applied the same aggregation procedure for anxiety, boredom, and performance. The level 2 file thus consisted of 721 units (sample size). The multilevel analytical approach allowed us to model the level 1 and level 2 datasets simultaneously (Raudenbush \& Bryk, 2002). Hence, the total variance for enjoyment, anxiety, and boredom, as well as for the achievement scores, can each be split into intersubject variance (interindividual variances on each of the mean scores for enjoyment, anxiety, boredom, and performance) and intrasubject variance (intraindividual variance for enjoyment, anxiety, boredom, and achievement across the four domains):

$$
\operatorname{Var}\left(Y_{\mathrm{ij}}\right)=\operatorname{Var}\left(\mathrm{u}_{0 \mathrm{j}}+r_{\mathrm{ij}}\right)=\tau_{00}+\sigma^{2}
$$

For enjoyment, for example, $\operatorname{Var}\left(Y_{\mathrm{ij}}\right)_{\mathrm{En}}$ represents the total variance of enjoyment across the four domains $i_{1}$ to $i_{4}\left(i_{1}=\right.$ mathematics, $i_{2}=$ Latin, $i_{3}=$ German, and $i_{4}=$ English) and all 721 students $j_{1}$ to $j_{721}(N=721)$. This total variance of the independent variables $\left(Y_{\mathrm{ij}}\right)$ can be split into an intrasubject variance $\left(\operatorname{Var}\left(r_{\mathrm{ij}}\right)\right.$ $\left.=\sigma^{2}\right)$ and an intersubject variance $\left(\operatorname{Var}\left(\mathrm{u}_{0 j}\right)=\tau_{00}\right)$. We can calculate the intraclass correlation $(\rho)$ using these two proportions of variance. The intraclass correlation reflects the proportion of intersubject variance $\tau_{00}$ relative to the total variance $\operatorname{Var}\left(Y_{\mathrm{ij}}\right)$ given $\operatorname{Var}\left(Y_{\mathrm{ij}}\right)=\tau_{00}+\sigma^{2}$ :

$$
\rho=\tau_{00} /\left(\tau_{00}+\sigma^{2}\right)
$$

Thus, the intraclass correlation can be interpreted as an indicator of the extent of domain specificity in each of the constructs assessed: The smaller the intraclass correlation, the higher the proportion of the intrasubject variance in the total 
variance, and, consequently, the more domain-specifically the construct is organized. Conversely, a high intraclass correlation would show that the total variance of the emotional experience might be primarily the result of differences between individuals (a large proportion of intersubject variance relative to the total variance), which would suggest a domain-general organization of emotional experiences. The present approach makes it possible to directly compare the intraclass correlations of enjoyment, anxiety, boredom, and performance and thus the extent of domain-specific organization for each of these constructs. To see whether intraclass correlations of our four constructs under investigation differed significantly from each other, we calculated $99 \%$ confidence intervals for each construct. We calculated these confidence intervals using a formula suggested by Fisher (1970), that was recently discussed by Ukoumunne (2002), as an adequate way of calculating confidence intervals for intraclass correlation coefficients in two-level hierarchical models.

\section{Results}

\section{Domain Specificity of Emotional Experiences}

The chi-square statistics and fit indices (NNFI, CFI, RMSEA) showed unacceptable model fit for both the general factor model (Model A) and the two models that assume emotion- or domain-specific factors (Models B and C; Table 1). Nevertheless, Model C showed a substantially better fit than did Model B, which in turn showed a slightly better fit than did Model A. The better fit of Model C compared with Model B indicates that differentiating the two-faceted data structure along domains better fits the data than does differentiating it along emotions. Model D showed a very good fit to the data (see Table 1). This means that, when taking method effects into account, it makes sense to assess students' emotional experiences based on four domain-specific latent factors.

Model E was an extended version of Model D in which, in addition to the four domain-specific factors, the four achievement scores were also included in the analyses (CU-MTMM model + achievement). The statistical characteristics of this model were acceptable (see Table 1). Table 2 shows the intercorrelations of the domain-specific factors, the intercorrelations of the achievement scores, as well as the correlations of the domain-specific factors with the achievement scores. Intercorrelations between the domain-specific factors (Table 2, upper left section) were generally very weak but were most strongly pronounced between English and German (.33), followed by Latin and German (.25), and Latin and mathematics (.20). The intercorrelations between the four domain-specific factors of Model $\mathrm{C}$ are not presented because of poor model fit. However, the intercorrelations of the domain-specific factors of Model C showed the same pattern, with correlation values being slightly higher than those in Model $\mathrm{E}$ (four domain- 
TABLE 1. Multitrait-multimethod Models: Results of Confirmatory Factor Analyses

\begin{tabular}{lccccc}
\hline \hline Models & $\chi^{2}$ & $d f$ & NNFI & CFI & RMSEA \\
\hline $\begin{array}{l}\text { (A) General factor } \\
\begin{array}{l}\text { (B) } 3 \text { emotion-specific } \\
\text { factors }\end{array}\end{array}$ & 1629.36 & 54 & .11 & .27 & .242 \\
$\begin{array}{l}\text { (C) } 4 \text { domain-specific }^{\text {factors }} \text { b } \\
\begin{array}{l}\text { (D) Model (C) emotion ratings } \\
\quad \text { as correlated uniqueness }\end{array}\end{array}$ & 1434.79 & 51 & .20 & .38 & .233 \\
$\begin{array}{l}\text { (E) Model (D) + acheivement } \\
\text { scores }^{\mathrm{b}}\end{array}$ & 920.44 & 48 & .56 & .68 & .191 \\
& 199.98 & 62 & .91 & .96 & .067
\end{tabular}

Note. $N=721$. NNFI $=$ Non-Normed Fit Index; CFI = Comparative Fit Index; RMSEA = Root Mean Square Error of Approximation. $\chi^{2}$ values for null models used to define the NNFI and CFI $=2323.38(d f=66)$ for models A to D and $3350.58(d f=120)$ for Model $\mathrm{E}$. aEmotion-specific factors are enjoyment, anxiety, and boredom. ${ }^{\mathrm{b}}$ Domain-specific factors and achievement scores refer to mathematics, Latin, German, and English. 'In models D and $\mathrm{E}$, correlated uniqueness were permitted.

specific factors, correlated uniquenesses). This indicates that the true relations of domain-specific emotional experiences are overestimated if method effects are not taken into account.

The intercorrelations between the achievement scores of the four domains were average in size (should be the range: $r=[.37, .56]$ alternatively it could be: range $=.37$ to $.56 ; M d n=.50$; see Table 2 , lower right area). We found a consistent pattern in the correlations between the four domain factors and the achievement scores (Table 2, lower left section). That is, we found the highest correlations within subject domains (mathematics $=.48$, Latin $=.32$, German $=.28$, and English $=.30$ ). We found the strongest correlations in the mathematics domain. Aside from the four within-domain correlations, there are no noteworthy correlations between the four domain-specific factors and achievement scores (the range: $|r|=[.01 ; .15]$ or alternatively: range $=.01$ to $.15 ; M d n[|r|]=.07)$.

\section{Degree of Domain Specificity in Discrete Emotions}

Table 3 presents the results of the multilevel analyses. As for the fixed effects, our results showed that across the four domains (mathematics, Latin, German, English) the overall mean was highest for enjoyment $\left(\gamma_{00}=2.98\right)$, followed by boredom $\left(\gamma_{00}=2.60\right)$, and anxiety $\left(\gamma_{00}=2.05\right)$. The estimated mean value for achievement across the four domains was $\gamma_{00}=4.05$. 
TABLE 2. Intercorrelations of Domain-Specific Factors, Correlations of Domain-Specific Factors With Achievement Scores, and Intercorrelations of Achievement Scores

\begin{tabular}{|c|c|c|c|c|c|c|c|c|}
\hline \multirow[b]{3}{*}{ Variable } & \multicolumn{8}{|c|}{$\begin{array}{l}\text { Model E } \\
\text { (domain-specific factors and achievement scores, } \\
\text { correlated uniqueness of emotion ratings) }\end{array}$} \\
\hline & \multicolumn{4}{|c|}{ Domain-specific factors } & \multicolumn{4}{|c|}{ Achievement scores } \\
\hline & Math & Latin & German & English & Math & Latin & German & English \\
\hline \multicolumn{9}{|c|}{ Domain-specific factors } \\
\hline Mathematics & 1.00 & & & & & & & \\
\hline Latin & .20 & 1.00 & & & & & & \\
\hline German & .06 & .25 & 1.00 & & & & & \\
\hline English & .00 & .14 & .33 & 1.00 & & & & \\
\hline \multicolumn{9}{|c|}{ Achievement scores } \\
\hline Mathematics & .48 & .10 & -.03 & -.04 & 1.00 & & & \\
\hline Latin & .08 & .32 & -.01 & .09 & .52 & 1.00 & & \\
\hline German & .05 & .13 & .28 & .15 & .37 & .47 & 1.00 & \\
\hline English & .01 & .10 & .00 & .30 & .42 & .56 & .52 & 1.00 \\
\hline
\end{tabular}


TABLE 3. Results of the Multi-level Analysis of the Extent of Domain Specificity of Anxiety, Boredom, and Achievement

\begin{tabular}{|c|c|c|c|c|c|c|c|c|c|}
\hline \multirow[b]{3}{*}{ Traits } & & & \multicolumn{5}{|c|}{ Random effects } & \multirow{2}{*}{\multicolumn{2}{|c|}{ Intra-class correlation }} \\
\hline & \multicolumn{2}{|l|}{ Fixed effects } & \multicolumn{4}{|c|}{ Level 2 effect $\left(\mathrm{u}_{0 \mathrm{i}}\right)$} & \multirow{2}{*}{$\frac{\text { Level } 1 \text { effect }\left(r_{i j}\right)}{\text { Variance within }}$} & & \\
\hline & $\begin{array}{l}\text { Average student } \\
\text { mean }\left(\gamma_{00}\right)\end{array}$ & $S E$ & $\begin{array}{l}\text { Variance between } \\
\text { students }\left(\tau_{00}\right)\end{array}$ & $d f$ & $\chi^{2}$ & $p$ & & $\rho$ & $\begin{array}{l}99 \% \text { confidence } \\
\text { interval of } \rho\end{array}$ \\
\hline Enjoyment & 2.98 & .02 & .148 & 709 & 1073.94 & $<.001$ & 1.061 & .123 & $.084-.161$ \\
\hline Anxiety & 2.05 & .03 & .405 & 709 & 2018.15 & $<.001$ & .812 & .333 & $.293-.372$ \\
\hline Boredom & 2.60 & .03 & .380 & 709 & 1738.64 & $<.001$ & .966 & .282 & $.243-.322$ \\
\hline Achievement & 4.05 & .03 & .417 & 709 & 2851.46 & $<.001$ & .541 & .448 & $.409-.486$ \\
\hline
\end{tabular}

Note. Intra-class correlation: $\rho=\tau_{00} /\left(\tau_{00}+\sigma^{2}\right)$. Students means and variations for enjoyment, anxiety, boredom and achievement were calculated from the respective scores in the academic domains of mathematics, Latin, German, and English. $N=721$. 
The analysis of the random effects showed that the levels of reported enjoyment, anxiety, and boredom, as well as performance, differed significantly across students (each $p<.001)$. The total variance $\operatorname{Var}\left(Y_{\mathrm{ij}}\right)=1.209$ for enjoyment, 1.217 for anxiety, 1.346 for boredom, and .931 for achievement. When comparing the variances of emotions and achievement, it is important to note that we obtained the three emotions using a 5-point Likert scale, whereas we assessed academic achievement (grades) on a 6-point scale. The intraclass correlation $(r)$, used here as an indicator of the extent of domain specificity, was .448 for achievement, .333 for anxiety, .282 for boredom, and .123 for enjoyment. The $99 \%$ confidence intervals for the intraclass correlations suggest that these four constructs, included in our study can be located at three statistically distinguishable levels of domain specificity. At the first level, there is achievement, which had the highest intraclass correlation (and, thus, a considerable degree of domain-transcendence), at the second level there is anxiety and boredom with moderate intraclass correlations (and, thus, a moderate degree of domain specificity), and at the third level there is enjoyment with the lowest intraclass correlation, which can therefore be considered the most domain-specific construct in the present study.

\section{Discussion}

\section{Domain Specificity of Emotional Experiences}

The poor fit of Models A, B, and C to the data indicates that it is not recommendable to group the two-facet items to one factor representing domain-general emotionality (Model A), to three factors representing domain-transcending emotions (Model B), or to four factors representing domain-specific emotionality (Model C). The poor fit of Model A clearly shows that the assumption of a general factor of domain-general emotionality, from whose strength one could infer the intensity of discrete emotional experiences in different domains, is not tenable. Furthermore, and central to the core research question in this study, is the poor fit of Model B, which shows that it does not make empirical sense to build emotionspecific factors. This means that one cannot presume that there are latent factors representing enjoyment, anxiety, and boredom from which one could infer the strength of the respective emotional experience in different subject areas. This finding clearly indicates a domain-specific organization of emotional experiences. The relatively poor fit of Model $\mathrm{C}$ to the data also shows that the assumption of latent factors concerning emotionality predicting discrete emotions across various domains such as mathematics, Latin, German, and English cannot be empirically confirmed. This lack of confirmation indicates that one cannot assume the existence of a latent factor domain-specific emotionality, from which one could draw conclusions regarding the intensities of discrete emotional experiences within a given domain. 
Although Models A, B, and C demonstrate an unacceptable fit to the data, Model C is substantially superior to Models A and B. A comparison of Models $\mathrm{B}$ and $\mathrm{C}$, which assume the existence of three or four factors, respectively, indicates that a structure that groups the three different emotions from the same academic domain (Model C) is superior to a structure that groups the items reflecting four different academic domains according to the same discrete emotion (Model B). This finding strengthens the assumption of a domain-specific organization of emotional experiences in that it is more empirically justifiable to group items that refer to different discrete emotions but one specific domain rather than to group items that refer to one discrete emotion but different domains. In other words, this finding shows that the relations between different emotional experiences within a domain are stronger than those between experiences of one specific emotion across different domains.

Along with assessing the four domain factors in Model D (CU model), we considered the potential effects of the three emotion factors by permitting correlated uniquenesses (i.e., we took into account the existence of method effects). The good fit of this model makes it clear that it is necessary to evaluate both domainspecific and emotion-specific factors simultaneously. In contrast to Model C, the intercorrelations of the factors in Model D are in better congruence with the data because method effects were taken into consideration in this model. Moreover, our findings showed that the relations between the domain-specific factors were overestimated if method effects were disregarded.

The very weak correlations between the four domain factors also clearly indicate a domain-specific organization of emotional experiences. A comparison with the intercorrelations of the four achievement scores reveals that, despite a similar correlation pattern, those are much stronger than the correlations between the factors reflecting domain-specific emotionality. This result indicates that emotions are more domain-specifically organized than is academic achievement. In addition, these findings showed weak correlations between the same emotional experiences in different domains that were regarded as relatively similar in nature, most notably between German and English, German and Latin, and mathematics and Latin. Although relationships between the same emotional experiences in the pure language-based subject areas (e.g., English, German) and mathematics are virtually zero, there are small correlations between emotional experiences in Latin and mathematics. In terms of the experienced emotions, Latin appears to have ties to both the mathematics and language-based domains - especially to German language.

The pattern of correlations between the four domain factors and the performance scores of Model E (between-network) indicate high convergent and discriminant validity of these factors, and yet strengthen the assumption of domainspecific emotional experiences. Using MTMM terminology (Marsh, 1988a), substantial correlations between domain-specific factors and achievement in 
matching school subjects provided strong support for the convergent validity of the factors, and the relative lack of correlations between scores in nonmatching school subjects supported the divergent validity of the factors. However, even the very weak correlations across domains reflect, in part, the between-domain relationships of the domain-specific factors (e.g., positive correlations between performance in German and emotional experiences in English). This reflection is an additional indicator of the high validity of the domain factor. It is notable that the within-domain correlations between the emotion factors and achievement also vary across subject areas, with the correlations for the mathematics domain being highest. This finding also indicates that the strength of the relationship between emotional experiences and performance is domain-specific.

In sum, our results are in line with our theoretical assumptions and clearly indicate domain specificity of emotional experiences. Both the findings from the competitive model testing and analysis of the model's within-network, as well as results of the convergent and discriminant validity of the domain-specific factors can be regarded as clear and consistent empirical support for our hypotheses.

\section{Extent of Domain Specificity of Discrete Emotions}

The findings of the HLM analyses show that enjoyment is the most intensively experienced emotion, followed by boredom and anxiety. As an indicator for the extent of domain specificity, we looked at the intraclass correlation $\rho$. The smaller the $\rho$ value, the greater the domain specificity in the given construct. Achievement showed the significantly lowest degree of domain-specific organization. With regard to the emotions, we observed a notable difference in the extent of domain specificity, with enjoyment being significantly more domain-specific than anxiety and boredom, which in turn did not significantly differ from each other in the extent of their domain specificity. That is, enjoyment proved to be the most domain-specific of the four constructs in that, even though the total variance of the three emotions across students and domains was approximately the same, the proportions of variance attributable to the differences between domains was relatively strong for all the three emotions, and particularly for enjoyment.

Even though we argue for a stronger consideration of the domain specificity of emotions, it may be worth mentioning that our findings do indicate that, for anxiety and boredom, there is a very weak factor representing "domain-general emotionality" (e.g., Model A). Across the domains, experiences of anxiety and boredom appear to vary less than experiences of enjoyment. To the knowledge of the authors, the question of situation specificity remains unexplored in the research literature with respect to boredom. Anxiety has been frequently discussed as an idiosyncratic emotion; a genetically transmitted habitualized disposition in which physiological processes, related to the subsystems of the limbic system (especially the amygdala), play a central role (Zeidner, 1998). Our findings suggest that anxi- 
ety is in fact a more domain-transcending emotion than is enjoyment. Furthermore, our results show that boredom is also less domain-specific than enjoyment. However, even for anxiety and boredom, when compared with academic performance, we conclude that the extent of domain specificity is strong enough to preclude further discussion of academic anxiety and boredom as domain-general constructs.

\section{Limitations}

There are some limitations of our study which might have implications for future research on the domain specificity of academic emotional experiences. Concerning the domains; investigated in this study, we concentrated on mathematics, Latin, German, and English, that is, on mathematics and three language classes. It would be interesting to integrate science in further analysis to see how it is related to mathematics. Further, it would be worth investigating emotions experienced not only in core subjects but also in subsidiary school subjects (e.g., music and art education). Thus, because our study focused only on four subject areas, further research on the extent of domain specificity for emotions assessed in other school subjects is warranted.

Concerning the emotions, we investigated three emotions which have been found to be salient in an academic environment and could be distinguished based on activation and valence, namely the emotions of enjoyment, anxiety, and boredom. However, our results are limited to these emotions. It would be worth investigating the domain specificity of other emotions which can be assumed to be important for students' psychological well-being in the classroom (e.g., enthusiasm, shame, guilt, and disappointment).

Finally, although our results indicate that the measurement of emotions using single-item measures in the current study was sufficiently valid (see Method section), it might be assumed that single-item scales assess enjoyment, anxiety, and boredom in a more global way than do multi-item scales which focus on specific facets of these emotions. Therefore, our results may have overestimated the relationships of emotional experiences across the various subjects as compared to results based on multi-item scales. However, this is merely a conjecture that cannot be drawn from our results and should be investigated in more detail. Future studies on the domain specificity of emotions using multi-item scales and accounting for scale reliability are encouraged. Further, the use of multi-item scales would enable an even more detailed level of analysis (see Bong, 2001, for analyzing domain specificity of motivational constructs with multi-item scales).

\section{Conclusions}

CFA-MTMM and HLM analyses proved to be appropriate for analyzing the two-faceted data structure of the present study. Results of these analyses provide 
critical empirical support for our assertion that emotional experiences are organized primarily in a domain-specific manner and that different emotions vary in their extent of domain specificity. Thus, these analyses are recommended for other studies utilizing a two-faceted design for investigating domain specificity of related constructs (e.g., other emotions, self-concepts, or aspects of self-regulated learning). Through the use of single-item scales, such studies can be conducted in a timely and cost-efficient manner. Nevertheless, single-item scales raise the question about the reliability of these scales.

A number of conclusions can be drawn from our findings on the domain specificity of emotional experiences. First, it appears to be more appropriate to speak of domain-specific rather than domain-transcending emotional experiences (e.g., enjoyment in mathematics instead of school-related enjoyment or enjoyment in class).

Second, from a research perspective, it appears to be appropriate to investigate students' emotions using domain-specific approaches. Within test anxiety research, an area that has been investigated most intensively in the achievement-related context, the majority of studies and intervention programs were conceptualized under the implicit assumption of a domain-transcending organization of emotional experiences (Zeidner, 1998). An exception is research on math-related anxiety (e.g., Miller \& Mitchell, 1994). For testing models that refer to emotional experiences and their relations to other constructs, the present research suggests that domainspecific designs may be most appropriate (e.g., for testing the control-value theory of emotions developed by Pekrun, [2000; in press], or a recently developed model linking achievement goals and affect by Linnenbrink \& Pintrich, [2002]). Consequently, the development of domain-specific instruments for the measurement of emotional experiences among students is also encouraged. Specifically, for the domain of mathematics and for students in grades 5-10, such an instrument already exists (Academic Emotions Questionnaire-Mathematics, AEQ-M; Pekrun, Goetz, \& Frenzel, 2006) and included scales for the assessment of enjoyment, pride, anxiety, anger, hopelessness, boredom, and shame. Adapted versions of this instrument could be used in future studies assessing academic emotions in different domains and contexts.

Third, from a practical perspective, these results suggest that it may also be helpful to generate domain-specific emotion-related counseling and intervention programs (see Everson et al., 1993). For example, it seems recommendable that attributional retraining, an effective treatment method fostering adaptive causal attributions and consequently positive emotional experiences (Hall, Hladkyj, Perry, \& Ruthig, 2004), and programs aimed at designing emotionally sound instruction (Astleitner, 2000; see also Goetz, Frenzel, Pekrun, \& Hall, 2005) should be implemented in a domain-specific way. Although domain-general programs may also have effects on domain-specific emotions, our results point to the fact that domain-specific programs might be more efficient. 
Finally, the present analyses show that only limited conclusions about a student's emotional experiences in a specific domain can be made from his or her experiences in another subject area. This finding stands in contrast to several studies indicating that teachers tend to view individual students' characteristics as habitual, domain-general attributes and not as domain-specific phenomena (see Marsh, 1993; Marsh, Smith, \& Barnes, 1983; Pohlmann, Möller, \& Streblow, 2004). Thus, one can assume that false judgments are often made by teachers with regard to the emotional experiences of their students in different domains. To prevent teachers from making false evaluations and to increase the effectiveness of school instruction (e.g., adaptive teaching; see Corno \& Snow, 1986; Snow \& Swanson, 1992), the findings of this study suggest that it is of critical importance for both teachers and educators to also be aware of the domain specificity of students' emotional experiences.

\section{REFERENCES}

Abu-Hilal, M. M., \& Bahri, T. M. (2000). Self-concept: The generalizability of research on the SDQ, Marsh/Shavelson model and I/E frame of reference model to the United Arab Emirates students. Social Behavior and Personality, 28, 309-322.

Astleitner, H. (2000). Designing emotionally sound instruction: The FEASP-approach. Instructional Science, 28, 169-198.

Bentler, P. M. (1990). Comparative fit indices in structural models. Psychological Bulletin, 107, 238-246.

Bong, M. (1998). Tests of the internal/external frames of reference model with subject-specific academic self-efficacy and frame-specific academic self-concepts. Journal of Educational Psychology, 90, 102-110.

Bong, M. (2001). Between- and within-domain relations of academic motivation among middle and high school students: Self-efficacy, task-value and achievement goals. Journal of Educational Psychology, 93, 23-34.

Bong, M., \& Skaalvik, E. M. (2003). Academic self-concept and self-efficacy: How different are they really? Educational Psychology Review, 15, 1-40.

Byrne, B. M. (1998). Structural equation modeling with LISREL, PRELIS, and SIMPLIS: Basic concepts, applications, and programming. Mahwah, NJ: Erlbaum.

Corno, L., \& Snow, R. E. (1986). Adapting teaching to individual differences among learners. In M. C. Wittrock (Ed.), Handbook of research on teaching (3rd ed., pp. 605-629). New York: Macmillan.

Dickhaeuser, O., \& Plenter, I. (2005). Letzes Halbjahr stand ich zwei. Zur Akkuratheit selbst berichteter Noten [On the accuracy of self-reported school marks]. Zeitschrift für Pädagogische Psychologie, 19, 219-224.

Efklides, A., \& Volet, S. (Eds.). (2005). Feelings and emotions in the learning process [Special issue]. Learning and Instruction, 15.

Everson, H. T., Tobias, S., Hartman, H., \& Gourgey, A. (1993). Test anxiety and the curriculum: The subject matters. Anxiety, Stress and Coping: An International Journal, 6, 1-8.

Fisher, R. A. (1970). Statistical methods for research workers. New York: Hafner.

Gottfried, A. E. (1982). Relationships between academic intrinsic motivation and anxiety in children and young adolescents. Journal of School Psychology, 20, 205-215.

Goetz, T. (2004). Emotionales Erleben und selbstreguliertes Lernen bei Schülern im Fach Mathematik [Emotions and self-regulated learning of students in mathematics]. Munich, Germany: Utz.

Goetz, T., Frenzel, C. A., Pekrun, R., \& Hall, N. (2005). Emotional intelligence in the context of learning and achievement. In R. Schulze \& R. D. Roberts (Eds.), Emotional intelligence: An international Handbook (pp. 233-253). Cambridge, MA: Hogrefe \& Huber. 
Hall, N. C., Hladkyj, S., Perry, R. P., \& Ruthig, J. C. (2004). The role of attributional retraining and elaborative learning in college students' academic development. The Journal of Social Psychology, 144, 591-612.

Hembree, R. (1990). The nature, effects, and relief of mathematics anxiety. Journal for Research in Mathematics Education, 21, 33-46.

Ingles, S. J., Scott, L. A., Lindmark, J. T., Frankel, M. R., Myers, S. L., \& Wu, S. (1992). National Education Longitudinal Study of 1988. First follow-up: Student component data file user's manual (Vol. 1). Washington, DC: U.S. Department of Education.

Jöreskog, K., \& Sörbom, D. (2002). LISREL 8.53. Chicago, IL: Scientific Software International.

Linnenbrink, E. A., \& Pintrich, P. R. (2002). Achievement goal theory and affect: An asymmetrical bidirectional model. Educational Psychologist, 37, 69-78.

Marsh, H. W. (1984). Relations among dimensions of self-attribution, dimensions of self-concept, and academic achievements. Journal of Educational Psychology, 76, 1291-1308.

Marsh, H. W. (1986). The self-serving effect (bias?) in academic attributions: Its relation to academic achievement and self-concept. Journal of Educational Psychology, 78, 190-200.

Marsh, H. W. (1988a). The content specificity of math and English anxieties: The high school and beyond study. Anxiety Research, 1, 137-149.

Marsh, H. W. (1988b). Multitrait-multimethod analyses. In J. P. Keeves (Ed.), Educational research, methodology, and measurement: An international handbook (pp. 570-580). Oxford, England: Pergamon.

Marsh, H. W. (1989). Confirmatory factor analyses of multitrait-multimethod data: Many problems and a few solutions. Applied Psychological Measurement, 13, 335-361.

Marsh, H. W. (1993). Academic self-concept: Theory measurement and research. In J. Suls (Ed.), Psychological perspectives on the self (Vol. 4, pp. 59-98). Hillsdale, NJ: Erlbaum.

Marsh, H. W., Balla, J. R., \& McDonald, R. P. (1988). Goodness-of-fit indexes in confirmatory factor analysis: The effect of sample size. Psychological Bulletin, 103, 391-410.

Marsh, H. W., Byrne, B. W., \& Craven, R. (1993). Overcoming problems in confirmatory factor analyses of MTMM data: The correlated uniqueness model and factorial invariance. Multivariate Behavioral Research, 27, 489-507.

Marsh, H. W., \& Grayson, D. (1995). Latent variable models of multitrait-multimethod data. In R. H. Hoyle (Ed.), Structural equation modelling: Concepts, issues, and applications (pp. 177-198). Thousand Oaks, CA: Sage.

Marsh, H. W., Smith, I. A., \& Barnes, J. (1983). Multitrait and multimethod analysis of the Self-Description Questionnaires: Student-teacher agreement on multidimensional ratings of student selfconcept. American Educational Research Journal, 20, 333-357.

Marsh, H. W., \& Yeung, A. S. (1996). The distinctiveness of affects in specific school subjects: An application of confirmatory factor analysis with the National Educational Longitudinal Study of 1988. American Educational Research Journal, 33, 665-689.

Miller, L. D., \& Mitchell, C. E. (1994). Mathematics anxiety and alternative methods of evaluation. Journal of Instructional Psychology, 21, 353-358.

Möller, J., \& Köller, O. (2001). Dimensional comparisons: An experimental approach to the Internal/External frame of reference model. Journal of Educational Psychology, 93, 826-835.

Möller, J., \& Köller, O. (2004). Die Genese akademischer Selbstkonzepte: Effekte dimensionaler und sozialer Vergleiche [On the development of academic self-concepts: The impact of social and dimensional comparisons]. Psychologische Rundschau, 55, 19-27.

National Center for Educational Statistics. (1986). High school and beyond, 1980: Sophomore cohort second follow-up (1984). Data file user's manual. Ann Arbor, MI: Inter-university Consortium for Political and Social Research.

Pekrun, R. (1992). The impact of emotions on learning and achievement: Towards a theory of cognitive/motivational mediators. Applied Psychology: An International Review, 41, 359-376.

Pekrun, R. (2000). A social-cognitive, control-value theory of achievement emotions. In J. Heckhausen (Ed.), Motivational psychology of human development (pp. 143-163). Oxford, England: Elsevier.

Pekrun, R. (in press). The control-value theory of achievement emotions: Assumptions, corollaries, and implications for educational research and practice. Educational Psychology Review.

Pekrun, R., Goetz, T., \& Frenzel, A. C. (2006). Academic Emotions Questionnaire-Mathematics 
(AEQ-M)-User's manual. Munich, Germany: University of Munich, Department of Psychology. Pekrun, R., Goetz, T., Titz, W., \& Perry, R. (2002a). Academic emotions in students' self-regulated learning and achievement: A program of qualitative and quantitative research. Educational Psychologist, 37, 91-105.

Pekrun, R., Goetz, T., Titz, W., \& Perry, R. P. (2002b, April). A social cognitive, control-value theory of achievement emotions: Social antecedents and achievement effects of students'domain-related emotions. Paper presented at the annual meeting of the American Educational Research Association, New Orleans, LA.

Pohlmann, B., Möller, J., \& Streblow, L. (2004). Zur Fremdeinschätzung von Schülerselbstkonzepten durch Lehrer und Mitschüler [On students' self-concepts inferred by teachers and classmates]. German Journal of Educational Psychology, 18, 157-169.

Raudenbush, S. W., \& Bryk, A. S. (2002). Hierarchical linear models. Applications and data analysis methods (2nd ed.). Thousand Oaks, CA: Sage.

Raudenbush, S., Bryk, A., Cheong, Y. F., \& Congdon, R. (2001). HLMTM 5. Hierarchical linear and nonlinear modeling. Lincolnwood, IL: Scientific Software International.

Richardson, F. C., \& Suinn, R. M. (1972). The Mathematics Anxiety Rating Scale: Psychometric data. Journal of Counseling Psychology, 19, 551-554.

Schutz P. A., \& Lanehart, S. L. (Eds.). (2002). Emotions in education [Special issue]. Educational Psychologist, 37(2).

\section{APPENDIX}

TABLE A1. Means $(M)$, Standard Deviations $(S D)$, and Intercorrelations of Single Items Scales and Achievement Scores

\begin{tabular}{|c|c|c|c|c|c|c|c|c|}
\hline Variable & bbreviations & $M$ & $S D$ & & 1 & 2 & 3 & 4 \\
\hline 1. Enjoyment & $\mathrm{M}$ & M_En & 3.00 & 1.17 & - & & & \\
\hline 2. Enjoyment & $\mathrm{L}$ & L En & 3.04 & 1.24 & .16 & 一 & & \\
\hline 3. Enjoyment & $\mathrm{G}$ & G En & 3.22 & 1.01 & .04 & .21 & - & \\
\hline 4. Enjoyment & $\mathrm{E}$ & E_En & 2.88 & 1.01 & .07 & .13 & .25 & - \\
\hline 5. Anxiety & $\mathrm{M}$ & M_An & 2.18 & 1.15 & -.57 & -.07 & .10 & .05 \\
\hline 6. Anxiety & $\mathrm{L}$ & $\mathrm{L}$ An & 2.25 & 1.24 & -.17 & -.47 & .01 & -.05 \\
\hline 7. Anxiety & $\mathrm{G}$ & G_An & 1.92 & .97 & -.09 & .05 & -.27 & -.16 \\
\hline 8. Anxiety & $\mathrm{E}$ & E_An & 1.78 & .95 & -.03 & -.01 & -.05 & -.50 \\
\hline 9. Boredom & $\mathrm{M}$ & $\mathrm{M}$ Bo & 2.50 & 1.15 & -.58 & -.18 & -.12 & -.07 \\
\hline 10. Boredom & $\mathrm{L}$ & $\mathrm{L}$ Bo & 2.57 & 1.28 & -.19 & -.75 & -.18 & -.14 \\
\hline 11. Boredom & $\mathrm{G}$ & G_Bo & 2.37 & 1.05 & -.10 & -.19 & -.57 & -.22 \\
\hline 12. Boredom & $\mathrm{E}$ & E_Bo & 2.80 & 1.14 & -.11 & -.11 & -.18 & -.59 \\
\hline 13. Performance & M & $\bar{M} \_A c$ & 4.03 & .97 & .40 & .10 & -.06 & -.01 \\
\hline 14. Performance & $\mathrm{L}$ & $\mathrm{L}$ Ac & 3.92 & 1.21 & .08 & .31 & .00 & .09 \\
\hline 15. Performance & G & G_Ac & 4.19 & .77 & .01 & .13 & .19 & .16 \\
\hline 16. Performance & $\mathrm{E}$ & E_Ac & 4.05 & .93 & -.02 & .05 & .00 & .31 \\
\hline
\end{tabular}

Note. Means and standard deviations of the single-item scales (measurement of discrete emotional experiences in various academic domains) are represented along with achievement scores. $\mathbf{M}=$ mathematics, $\mathrm{L}=$ Latin, $\mathrm{G}=$ German, $\mathrm{E}=$ English. $p<.05$ for $|r| \geq .07 ; p<.01$ for $|r| \geq .10$; $p<.001$ for $|r| \geq .12 . N=721$. 
Snow, R. E., \& Swanson, J. (1992). Instructional psychology: Aptitude, adaptation, and assessment. Annual Review of Psychology, 43, 586-626.

Steiger, J. H., \& Lind, J. C. (1980, June). Statistically based tests for the number of common factors. Paper presented at the Psychometric Society Annual Meeting, Iowa City, IA.

Stevenson, H. W., \& Newman, R. S. (1986). Long-term prediction of achievement and attitudes in mathematics and reading. Child Development, 57, 646-659.

Tucker, L. R., \& Lewis, C. (1973). A reliability coefficient for maximum likelihood factor analysis. Psychometrika, 38, 1-10.

Turner, J., \& Schallert, D. (2001). Expectancy-value relationships of shame reactions and shame resilience. Journal of Educational Psychology, 93, 320-329.

Ukoumunne, O. C. (2002). A comparison of confidence interval methods for the intraclass correlation coefficient in cluster randomized trials. Statistics in Medicine, 21, 3757-3774.

Watson, D., \& Tellegen, A. (1985). Toward a consensual structure of mood. Psychological Bulletin, 98, 219-235.

Weiner, B. (1985). An attributional theory of achievement motivation and emotion. Psychological Review, 92, 548-573.

Widaman, K. F. (1985). Hierarchically nested covariance structure models for multitrait-multimethod data. Applied Psychological Measurement, 9, 1-26.

Zeidner, M. (1998). Test anxiety: The state of the art. New York: Plenum.

\begin{tabular}{lllllllllllll}
\hline \hline 5 & 6 & 7 & 8 & 9 & 10 & 11 & 12 & 13 & 14 & 15 & 16 \\
\hline
\end{tabular}

\begin{tabular}{rrrrrrrrrrrrrrr}
.$\overline{.42}$ & $\overline{-}$ & & & & & & & & & \\
.36 & .32 & $\overline{-}$ & & & & & & & & \\
.30 & .39 & .44 & $\overline{-}$ & & & & & & & \\
.41 & .18 & .13 & .05 & $\overline{-}$ & & & & & & \\
.14 & .35 & -.02 & .02 & .34 & - & & & & & \\
.04 & .07 & .22 & .08 & .30 & .34 & - & & & & \\
.07 & .08 & .15 & .33 & .27 & .26 & .39 & - & & & \\
-.29 & -.10 & .07 & .05 & -.24 & -.10 & -.01 & -.01 & - & & \\
-.01 & -.26 & .06 & -.10 & -.08 & -.18 & .06 & .09 & .52 & - & \\
.04 & -.10 & -.14 & -.07 & -.06 & -.09 & -.12 & -.04 & .37 & .47 & -.04 & \\
.08 & -.06 & -.02 & -.23 & -.00 & -.02 & .04 & -.03 & .42 & .56 & .52 & - \\
\hline
\end{tabular}

